\title{
Entre livros e leitores: o catálogo de obras da biblioteca do Gabinete de Leitura de Jundiaí
}

Paulo Henrique de Oliveira ${ }^{1}$

Resumo: O presente artigo objetiva apresentar o trabalho metodológico e quantitativo desenvolvido com o catálogo de obras do Gabinete de Leitura de Jundiaí. A pesquisa baseou-se na catalogação e ordenação do catálogo com referência à Classificação Decimal Dewey (CDD). Essa classificação possibilitou observar aspectos qualitativos, como as preferências de leitura dos sócios e frequentadores do Gabinete de Leitura, revelando ainda um universo de circulação de livros, de práticas de leitura e um breve panorama do campo editorial brasileiro, nas primeiras décadas da República - 1910/1930.

Palavras-Chave: Gabinete de Leitura; Acervo; Catálogo de Obras; História da Leitura.

Abstract: The present article aims to present the methodological and quantitative work developed with the works catalog of the Jundiaí Reading Cabinet. The research was based on the cataloging and ordering of the catalog with reference to the Dewey Decimal Classification (CDD). This classification made it possible to observe qualitative aspects, such as the reading preferences of members and readers of the Reading Cabinet, also revealing a universe of circulation of books, reading practices and a brief panorama of the Brazilian publishing field in the first decades of the Republic - 1910/1930.

Keywords: Reading Cabinet; Collection; Works Catalog; History of Reading.

O Gabinete de Leitura da cidade de Jundiaí, localizada na região oeste do Estado de São Paulo, fundado no ano de 1908 por um grupo de trabalhadores ferroviários da Companhia Paulista de Estradas

${ }^{1}$ Professor de História no Colégio da Polícia Militar de São Paulo e na Secretaria Municipal de Educação de São Paulo. Mestre em História Social pela PUC/SP. Email: paulohenrique.oliveira@ig.com.br.

Revista Vernáculo n. ${ }^{\circ} 41$ - primeiro semestre $/ 2018$

ISSN 2317-4021 
de Ferro, possui em seu acervo de documentos um catálogo de obras, criado pelo bibliotecário da instituição em 1957, contendo a descrição manuscrita de 9.027 livros, que estão arrolados em uma classificação de ordem numérica, seguida por título da obra e o nome do autor.

O Gabinete de Leitura foi a primeira biblioteca pública da cidade de Jundiaí, marcando a tentativa de um grupo de operários de promoverem o acesso ao livro e à leitura na região. O presente trabalho objetiva apresentar a análise metodológica e quantitativa desenvolvida com o catálogo de obras da instituição, resultado de pesquisa de mestrado defendida na PUC/SP em 2015.

A pesquisa baseou-se na catalogação e ordenação desse catálogo com referência à Classificação Decimal Dewey (CDD). Essa classificação possibilitou observar aspectos qualitativos, como as preferências de leitura dos sócios e frequentadores do Gabinete de Leitura, revelando ainda um universo de circulação de livros, de práticas de leitura e um panorama do campo editorial brasileiro, nas primeiras décadas da República - 1910/1930.

O catálogo de obras do Gabinete de Leitura de Jundiaí resistiu ao tempo. E, no processo da pesquisa, essa fonte configurou-se como uma gama de informações a serem ordenadas e interpretadas.

Ordenar o caos da informação é a única possibilidade de dar sentido a um determinado universo informativo. Assim, a pesquisa observou, no catálogo de obras, a possibilidade de se traduzir o acervo da instituição na síntese dos livros comprados ao longo de sua

Revista Vernáculo n. ${ }^{\circ} 41$ - primeiro semestre $/ 2018$

ISSN $2317-4021$ 
existência, de acordo com as preferências dos leitores, pois estes escolhiam os livros que seriam comprados para o acervo, conforme as fontes consultadas evidenciaram.

Essa análise identificou a predominância de determinadas áreas do conhecimento como Ciências Sociais, História e Literatura/Retórica. Para esta última, o gênero Romance prevalece, demonstrando o interesse do público leitor por essa temática.

Robert Darnton chama a atenção para os perigos de uma história quantitativa e, portanto, em escala ampla sobre os estudos do livro e da leitura; salienta que as investigações de acervos, catálogos de bibliotecas e de livrarias, requerentes de uma divisão por gêneros e classes literárias, ou seja, um modo quantitativo de análise pode, de certo modo, adentrar em um ordenamento desarranjado, na tentativa de interpretar o mundo social.

Darnton sugere que arrolar livros de forma quantitativa pode limitar as possibilidades de análise do historiador, por não abarcar as singularidades do leitor em sua relação com os livros e em sua prática de leitura. Assim, o historiador propõe uma análise sobre: inventários pós-morte, registro de compras de livros, registro de consulta ou retirada de livros, que possibilite uma análise qualitativa, podendo até mesmo traçar perfis de público leitor ${ }^{2}$.

Para Darnton, a análise qualitativa sobre acervos e catálogos de obras evidencia uma gama de aspectos sobre os leitores e sobre a

${ }^{2}$ DARNTON, Robert, O beijo de Lamourette: mídia, cultura e revolução, 2010. Revista Vernáculo n. ${ }^{\circ} 41$ - primeiro semestre /2018 
própria vida humana, na constituição de suas relações com o universo do impresso. No exame sobre o Catálogo de Obras do Gabinete de Leitura de Jundiaí a análise quantitativa possibilitou uma interpretação qualitativa, ao demonstrar a composição dos gêneros literários presentes na biblioteca, e os indícios sobre as formas de aquisição desses livros sugerem ainda as preferências dos leitores.

Esse estudo se insere ainda dentro do campo de estudos da história do livro e da história da leitura. Por serem espaços destinados a abrigar livros e um cenário compósito de uma sociabilidade livresca, Gabinetes de Leitura estão intrinsecamente relacionados aos trabalhos que objetivam investigar os muitos caminhos e lugares do livro e as inúmeras formas de leitura (apropriações) nas mais distintas circunstâncias espaciais e temporais.

Apresentando-se como mecanismos de suporte para a prática da leitura, os Gabinetes de Leitura convergem, dentre muitas outras possibilidades, para o próprio campo de análise do objeto material e de consumo que possui destaque em seu interior: o livro.

O caminho escolhido para o desenvolvimento desta análise não foi gratuito: converge com os indícios identificados na análise das fontes, todavia, representa apenas uma das possibilidades do percurso investigativo definido para essa pesquisa. O catálogo de obras do Gabinete de Leitura de Jundiaí possibilita muitos outros caminhos de investigação, podendo traçar outras abordagens, haja vista a

Revista Vernáculo n. ${ }^{\circ} 41$ - primeiro semestre /2018

ISSN 2317-4021 
potencialidade de seu acervo documental, o que possibilita outras compreensões sobre este múltiplo objeto de estudo.

\section{Compondo um acervo}

Se toda a biblioteca é um espelho do universo, então todo catálogo será espelho de um espelho ${ }^{3}$.

Tentar reunir o conhecimento humano produzido nas mais diferentes épocas e lugares é tarefa antiga. Da tableta de argila dos Sumérios aos impressos saídos dos prelos da idade moderna, muitos foram os homens (escribas, sacerdotes, nobres, príncipes, entre outros) que se empenharam em reunir formas de escrita, livros, manuscritos e outros impressos ${ }^{4}$. Essa reunião de obras acabou por se constituir na ação de se formarem acervos, acumulando-se o pensamento filosófico, artístico e científico do homem, em um desejo sempre inalcançável de se alcançar o conhecimento sobre o universo.

A imagem de uma biblioteca e a figura do bibliotecário são possivelmente a síntese mais atual e usual, quando se pensa na reunião de muitos livros e naquele responsável por reuni-los. Mesmo com os avanços da informática e com os inúmeros acervos documentais e bibliográficos reunidos e dispersos na internet, a qualquer leitor navegador, a biblioteca e o bibliotecário são ainda imperativos na

${ }^{3}$ MANGUEL, Alberto. A biblioteca à noite. São Paulo: Companhia das Letras, 2006, p. 52.

${ }^{4}$ Para se aprofundar sobre a história da construção e destruição das bibliotecas, consultar: POLASTRON, Lucien X. Livros em chamas: a história da destruição sem fim das bibliotecas. Rio de Janeiro: José Olympio, 2013.

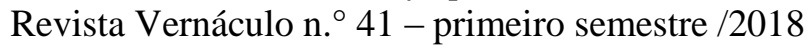

ISSN 2317-4021 
ordem dos livros 5 . Enquanto a biblioteca é uma coleção de livros organizados e que serve aos que procuram livros para ler, o bibliotecário é o responsável por escolhê-los, ordená-los e dispô-los aos leitores para serem lidos. Em uma metáfora de Chartier, "o bom bibliotecário é um jardineiro que poda sua biblioteca" 6 .

No Gabinete de Leitura de Jundiaí, a biblioteca foi implantada logo na fundação da instituição. Sua criação era a primeira, dentre as três finalidades pretendidas pelos fundadores. Durante quatro anos consecutivos (1908-1911), os sócios contribuintes elegeram João Xavier Dias da Costa para exercer a função de bibliotecário. Ao que se conseguiu apurar sobre sua vida, João da Costa era jornalista, colaborador de alguns jornais de Jundiaí, como $A$ Borboleta e $A$ Comarca, e escreveu para o periódico A Elite, que passou a circular em Jundiaí em 1911, “com conteúdo crítico, humorístico, literário e noticioso" $"$.

Incumbido de registrar as consultas realizadas aos livros do acervo, fazer um balanço da biblioteca, expondo suas condições, e apresentá-lo anualmente à diretoria do Gabinete de Leitura, João da Costa, segundo os registros em ata demonstram, era o sócio mais indicado para tal tarefa. Ao se ler a ata das reuniões de Assembleias Gerais para a eleição do bibliotecário, nota-se que a escolha de seu nome é sempre unânime entre os votantes.

${ }^{5}$ CHARTIER, Roger. A aventura do livro: do leitor ao navegador. São Paulo: Editora UNESP, 1999.

${ }^{6}$ Ibidem, p. 127.

${ }^{7}$ PAULA, Op. cit., p. 1.

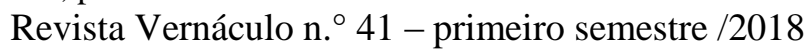

ISSN 2317-4021 
Competiam ao bibliotecário muito mais as tarefas de administrar a biblioteca e zelar por ela do que escolher os livros que comporiam o acervo. A diretoria do Gabinete de Leitura nomeava comissões que eram responsáveis por comprar livros e angariar doações, sem necessariamente ter a participação do bibliotecário. Essas comissões eram definidas trimestralmente durante uma Assembleia Geral.

A comissão nomeada para efetuar a compra de livros é composta pelos senhores João Xavier Dias da Costa, José Martins e Thomaz Silveira. $(02 / 03 / 1909)$.

Para o presente trimestre foram nomeados para a comissão de compra de livros os sócios senhores Laurentino Santos, Pedro Penteado de Castro e José Martins. (11/01/1910).

Pelo senhor presidente foi proposto e aceito por todos a nomeação dos senhores Morivalde Costa, Laurentino Santos e Theodoro Paes para a compra de livros do corrente anno (06/01/1911).

Foi deliberado a nomeação dos senhores Conrado Offa e Joaquim da Silva Cunha Santos para a compra de livros que em breve será feita. $(17 / 02 / 1913)$

Nomeados em Assembléia Geral os senhores Alfredo Elias e Ignácio Ventania para comporem a comissão para a compra de livros. $(15 / 03 / 1914)^{8}$.

Após a formação das comissões, os livros que seriam comprados eram escolhidos durante a mesma assembleia, de acordo com as escolhas dos sócios participantes das reuniões. Porém, em

${ }^{8}$ Livro de Registro das Atas de Assembleia Geral.

Revista Vernáculo n. ${ }^{\circ} 41$ - primeiro semestre /2018

ISSN 2317-4021 
nenhuma das atas consultadas há o registro dos títulos solicitados ou menção à quantidade de livros a serem comprados por cada comissão. Ainda assim, a comissão consultava os sócios e muito provavelmente suas "preferências literárias" emergiam naquele momento, quando podiam interferir na escolha dos livros.

Os sócios reunidos nesta Assembléia Geral elegeram os livros a serem comprados por esta sociedade. (02/03/1909).

A comissão nomeada para a compra de livros vae apurar com os sócios os livros que deverão ser comprados. (11/01/1910).

Deve a referida comissão nomeada consultar os sócios para a escolha dos livros (06/01/1911).

Solicita-se a comissão que averigue com os sócios os livros para serem comprados, como sempre se tem feito $(17 / 02 / 1913)^{9}$.

Schapochink e Martins, em seus estudos sobre os Gabinetes de Leitura nas Províncias de São Paulo e Rio de Janeiro, no século XIX, observam que comumente as diretorias dos Gabinetes realizavam a escolha dos livros que seriam comprados. Posteriormente formavam um catálogo de títulos, que era impresso nas tipografias locais, ficava nas sedes dos Gabinetes de Leitura e também era enviado aos jornais locais para publicação e conhecimento do público. No Gabinete de Leitura de Jundiaí o processo ocorria de modo diferente.

Os livros eram escolhidos, porém as formas pelas quais eles eram comprados não são mencionadas nas atas. Após a formação das

${ }^{9}$ Idem.

Revista Vernáculo n. ${ }^{\circ} 41$ - primeiro semestre /2018

ISSN 2317-4021 
comissões, não é possível averiguar se eram comprados em livrarias, editoras ou sob algum tipo de encomenda. Os estatutos de 1908, reformados em 1911, mencionam apenas que $20 \%$ do saldo existente no caixa da instituição seriam destinados para a compra de livros. Todavia, também não é possível saber quais os valores mensais desses saldos, para que se pudesse ter uma quantia aproximada do que era destinado à compra de livros. E, ao que se pôde verificar, as atas não mencionam a impressão de catálogos, nem a sua divulgação na imprensa local.

No ano de 1908 o jornal da instituição, O Gabinete, tornava pública a situação inicial da biblioteca e pedia, a quem pudesse, donativos de livros, jornais e revistas.

Movimento do Gabinete desde a fundação

Existem na bibliotheca 104 obras - com 184 volumes.

Sahiram 75 obras.

Foram consultados 2 volumes.

Folhetos existem diversos, 17.

Jornaes da capital 3 - Jornaes do interior 4 - Jornaes desta cidade 2

Aos que receberem esta folha, pede-se uma oferta de um livro, revista, opusculo, manuscripto ou outra qualquer dadiva util a esta casa de utilidade publica $^{10}$.

Com a formação das comissões, esse número começou a crescer, aumentando significativamente o acervo da biblioteca. Pelos Anuários Estatísticos de São Paulo a biblioteca apresentava o seguinte

${ }^{10}$, O Gabinete: Orgam do Gabinete de Leitura Jundiahyense. Anno I, $\mathrm{N}^{\circ} 1$, p. 4. Revista Vernáculo n. ${ }^{\circ} 41$ - primeiro semestre $/ 2018$ 
panorama: 800 obras com 1.060 volumes, em 1910; 1.160 obras com 1.298 volumes, em 1911; 1.276 obras com 1.325 volumes, em $1912^{11}$.

No mês de dezembro de 1912, o bibliotecário, cujo nome não é citado, registrava em ata de reunião da diretoria o movimento da biblioteca:

Obras retiradas para leitura -1.896 Volumes

Obras consultadas por pessoas estranhas á sociedade -212 Volumes

Existia o ano passado - 1.298 Volumes

Adquiridos por compra - 97 volumes

Foram inutilizados por imprestáveis - 119 volumes

Em resumo existem atualmente 1.276 volumes ${ }^{12}$.

Como se observa, o acervo pouco se alterara, tendo até mesmo uma diminuição de 1.298 volumes (1911) para 1.276 (1912), mesmo com a compra de 97 volumes novos. Os volumes descartados, por serem considerados "imprestáveis", certamente o eram em decorrência da frequente circulação. Possivelmente os exemplares eram constantemente consultados e/ou retirados pelos leitores, e o registro dos 1.896 volumes retirados para a leitura no respectivo ano demonstra essa frequência.

Em 1913, a biblioteca teve um acréscimo de 100 títulos no acervo, passando a ter 1.376 obras com 1.454 volumes. Esse número se manteve para o ano de 1914. Em 1916, o número subiu para 1.476 obras com 1.554 volumes, chegando a 1.503 obras com 2.457 volumes

${ }^{11}$ Anuários Estatísticos de São Paulo 1910-1926, p. 194-199.

${ }^{12}$ Livro de Registro das Atas da Diretoria, 25.12.1912, p. 8.

Revista Vernáculo n. ${ }^{\circ} 41$ - primeiro semestre /2018

ISSN 2317-4021 
em 1917, mantendo esse mesmo número de obras para o ano de 1918, porém diminuindo o número de volumes para 2.357.

Em 1919, a biblioteca apresentava 1.500 livros, três a menos que no ano anterior, contendo 1.824 volumes, 533 a menos. $\mathrm{O}$ motivo da perda desses volumes não é citado. Possivelmente foram descartados por desgaste.

No ano de 1920, o número de obras subiu para 1.655, passando a ter 2.150 volumes, mais que dobrando para o ano de 1922, quando a biblioteca passou a ter 4.120 obras com 5.271 volumes, mantendo essa quantidade até o ano de $1926^{13}$.

Além das compras que eram realizadas pelas comissões, os livros também chegavam à biblioteca do Gabinete de Leitura por meio de doações. Sócios, políticos e civis de Jundiaí doavam livros.

As comissões eram também formadas para angariar donativos à instituição. Nesse processo, livros somavam-se a outras modalidades de doações e benfeitorias. No dia 18 de Janeiro de 1911, em reunião da diretoria que passava a assumir o exercício do respectivo ano, registravam-se os agradecimentos aos que haviam feito doações ao Gabinete de Leitura no ano anterior, dentre elas, livros:

\footnotetext{
Agradecemos ao senhor, Laurentino Santos, pelo seu tino e abnegação na comissão de angariar livros e aos senhores:

Gabriel Peuliar pela doação de 70 volumes

Eloy Chaves 30 volumes

Benedito Pacheco 30 volumes
}

${ }^{13}$ Anuários Estatísticos de São Paulo. Op. cit.

Revista Vernáculo n. ${ }^{\circ} 41$ - primeiro semestre /2018

ISSN $2317-4021$ 
Manuel Derruda 16 volumes

Dr. J. Ulhôa 12 Volumes

Antonio C. Sobrinho 6 volumes

Manuel Martins 4 volumes

Antonio E. Sobrinho 4 volumes

Bianco Pereira 3 volumes

Pedro Peutrear 1 volume

Francisco Sucupira 1 volume

Luiz Caldas 1 volume

José Martins 3 volumes

Sérgio Martins 2 volumes

Matias M. Pereira 2 volumes ${ }^{14}$.

Essas doações ocorreram com frequência em diferentes anos. Não é possível precisar a quantidade de livros doados em cada ano, pois em muitas atas registravam-se apenas os agradecimentos às pessoas que doaram, sem, contudo, se mencionar o número de obras doadas.

A directoria agradece ao senhor Joaquim Silva Rocha pelos livros cedidos a sociedade (03/04/1912).

Votos de louvor aos senhores José Camargo e Manuel Ferreira pelos livros doados ao gabinete de leitura (05/06/1914).

Um voto de profundo agradecimento ao Sr. Alceu Guimaraes pelos livros doados a sociedade $(15 / 02 / 1918)^{15}$.

Esse cenário demonstra como a constituição do acervo não obedecia a um padrão. Tanto as comissões formadas para comprar ou angariar livros quanto qualquer cidadão jundiaiense poderiam contribuir para o crescimento da biblioteca do Gabinete de Leitura doando livros.

${ }^{14}$ Livro de Registro das Atas da Diretoria, 18.01.1911, p. 2.

${ }^{15}$ Livro de Registro das Atas da Assembleia Geral.

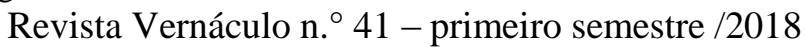

ISSN 2317-4021 
Jornais e revistas também compunham esse acervo. A diretoria assinava os jornais: A Folha, Ferroviário, Correio de Campinas, Correio Paulistano, O Jundiahense, Folha da Tarde, Telephone, O Jornal, Comércio e o Livre Pensador. Dentre os periódicos, constavam A Elite e o Escal. Dentre as revistas, eram assinadas: A cigarra, Biblioteca Cor de Rosa, Feminina, Novíssima, D. Quixote e Brasil.

Esses impressos variavam entre publicações locais, de outras cidades e nacionais. Eram jornais e "revistas de cultura", "revistas de variedades", "revistas ilustradas", que abordavam desde questões literárias, passando por arte, moda, costumes, humor, esportes, economia e comércio ${ }^{16}$. Desse modo, os sócios e frequentadores do Gabinete de Leitura poderiam se manter informados das variedades e dos acontecimentos.

Como esse acervo era organizado dentro da biblioteca?

\section{Ordenando o desordenado}

De acordo com o bibliotecário Luís Milanesi, bibliotecas públicas têm a função de prestar serviços, através de uma coleção de livros organizados. Dentro do acervo de uma biblioteca, há inúmeros discursos literários, dos quais os leitores buscam se apropriar. Para tanto, é preciso que as partes (livros) do todo (acervo) estejam ordenadas com objetividade, em vista da localização posterior de uma

${ }^{16}$ CRUZ, Heloisa de Faria (Org.). São Paulo em Revista: catálogo de publicações da imprensa cultural e de variedades paulistana 1870-1930. (Coleção memória, documentação e pesquisa, 4). São Paulo: Arquivo do Estado, 1997.

Revista Vernáculo n. ${ }^{\circ} 41$ - primeiro semestre $/ 2018$

ISSN 2317-4021 
dessas partes pelos leitores ${ }^{17}$. É preciso a desordem para que se estabeleça a ordem. Encontrar um livro em uma biblioteca pode ser uma tarefa simples, se houver uma indicação que oriente com exatidão a sua localização dentro do acervo. Segundo Milanesi, "essa indicação é feita pelo bibliotecário, avaliando a ordenação das partes para se formar um todo lógico e coerente" ${ }^{" 18}$.

Desse modo, acervos até mesmo idênticos podem ser organizados de modos diferentes, de acordo com cada bibliotecário, pois o conhecimento humano não tem o mesmo sentido para todos e sua expressão, em forma de texto, obedece a diferentes arranjos.

Como os bibliotecários do Gabinete de Leitura de Jundiaí eram escolhidos anualmente pelos próprios sócios, notadamente a constituição e a organização do acervo passavam por diferentes olhares e lógicas de ordenação.

Um registro fotográfico datado de 1926 mostra que os livros da biblioteca do Gabinete de Leitura ficavam em estantes dispostas atrás de um balcão, onde possivelmente o bibliotecário e outros colaboradores permaneciam a postos para pegarem os livros solicitados pelos sócios e demais frequentadores.

Observando-se a imagem, pode-se perceber que o acervo não ficava à livre disposição, para que os leitores pudessem manuseá-lo, retirando e recolocando os livros nas estantes. O papel do bibliotecário

${ }^{17}$ MILANESI, Luís. Ordenar para Desordenar: centros de cultura e bibliotecas públicas. Editora Brasiliense, 1986.

${ }^{18}$ Ibidem, p. 33.

Revista Vernáculo n. ${ }^{\circ} 41$ - primeiro semestre $/ 2018$

ISSN 2317-4021 
e/ou encarregados da biblioteca era necessário para mediar a consulta das obras e o contato físico entre leitores e livros.

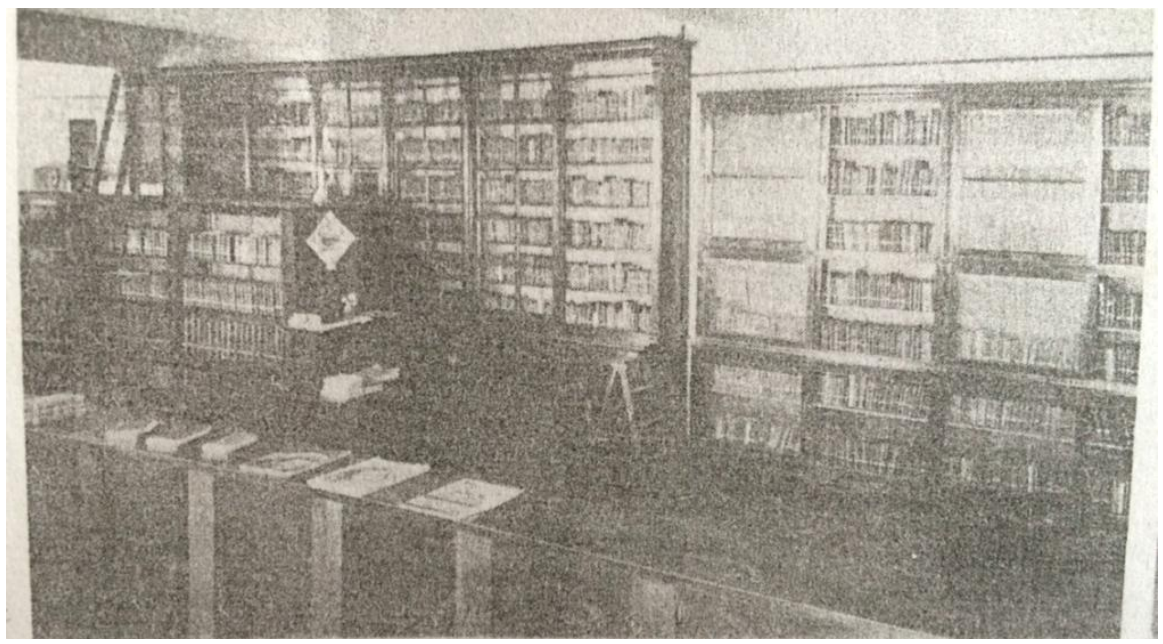

Figura 1 - Estantes da biblioteca do Gabinete de Leitura de Jundiaí, 1926.

Fonte: FERREIRA, 2014.

Sobre a maneira de organização dos livros dentro das estantes pelos bibliotecários, pode-se supor que eles eram ordenados, na biblioteca, desde a sua fundação em 1908, de forma numérica, seguindo a sequência arábica $(1,2,3,4,5 \ldots)$, sem qualquer relação com os títulos, seus temas e autores.

Em janeiro de 1945, certamente no período em que uma nova diretoria do Gabinete de Leitura assumiu o exercício de suas funções, uma comissão formada para organizar o acervo da instituição apresentou em folhas avulsas seu parecer sobre a situação da biblioteca e dos livros existentes.

Revista Vernáculo n. ${ }^{\circ} 41$ - primeiro semestre /2018

ISSN 2317-4021 
Aos senhores eleitos para o cargo de diretor da Biblioteca do Gabinete de Leitura (...) de Jundiaí, impusemos ao senhor presidente, Benedito de Godoy Ferraz, uma condição para assumirmos nossas funções: a Diretoria providenciaria um inventário e balanço da biblioteca. Atendidos nessa condição plenamente, assumimos então o nosso cargo, com o conhecimento absoluto da quantidade dos volumes da biblioteca. A comissão incumbida desse balanço foi constituída dos senhores Ivo Serafim, Potyguara Offa, Alcides Pereira da Silva e Deodoro Pestana, sob a minha direção. As fichas do levantamento bem dizem o que foi esse serviço, cuja principal virtude foi a de nos proporcionar meios para sabermos da verdadeira situação da biblioteca. A situação não está muito promissora; havia falta de continuidade no número de volumes nas estantes, existiam muitos números vagos - inexplicadamente - faltas de numeração etc. Há a tradição oral de que cada diretor bibliotecário adotou um jeito específico de numeração, escolhendo para o início determinado milhar - ex. 4000 - sem a preocupação com os números vagos na ordem da numeração. Corre outro rumor, também de tradição oral, de que a biblioteca fora assaltada duas vezes, uma em 1930 e outra em 1932, tendo havido subtração de livros. Ora, diante dessas notícias, era natural que não quiséssemos assumir as funções de devotos da biblioteca, sem a tranquiilidade na medida por nós solicitada - não nos convinha comprar novos exemplares.

A providência do balanço foi salutar porque mostrou a verdadeira situação da biblioteca, ficando a Diretoria, bem como os senhores associados, sabendo da quantidade e da qualidade do material que nos era entregue para organizar em biblioteca fichada e de contrastes perfeito para o gênero de leitura de cada livro.

Com esse inventário foi fixado o marco inicial de reformas de algumas utilidades para o Gabinete e seus associados.

Revista Vernáculo n. ${ }^{\circ} 41$ - primeiro semestre /2018

ISSN 2317-4021 
Confirmamos que não nos lançaríamos a tomar conta do cargo sem sabermos quantos e quais volumes existentes na biblioteca, e isto foi amplamente corrigido - a biblioteca possuía 3.858 volumes.

A numeração estava no número 4.989, existiam nas estantes números de 3.858 estavam vagos ou faltantes 1.131 volumes. 3 livros com a numeração em duplicata, conforme constam das fichas do balanço.

Praticamente, pois, iniciamos a nova pasta de abertura da biblioteca com 3.858 volumes. Se quisermos conhecer a quantidade de volumes adquiridos ou oferecidos ao Gabinete é o bastante preenchermos as claras as fichas do balanço e apanharmos pelos livros das estantes. A ordem do senhor Ferraz era a de preenchermos os números vagos, para depois reiniciarmos a numeração. Esta ordem foi transmitida a Silvete encarregada da biblioteca, cabendo a ela, organizar um apanhado nesse sentido.

O reinicio da numeração na nova pasta deu-se com o número 4.990 "O Rio de Janeiro do Meu Tempo" de Luiz Eduardo. Todos os demais volumes comprados ou adquiridos por doação pelo Gabinete vão para os números vagos, de sorte, que fácil será conhecermos a atual situação fazendo um apanhado dos números preenchidos, cujas vagas constam das folhas acima referidas.

Estou às ordens da Digna Diretoria atual para melhores esclarecimentos.

Desejo receber de volta essa explicação para salvaguarda da minha empreitada (Jundiaí $16 / 01 / 1945)^{19}$.

${ }^{19}$ Parecer da comissão responsável por organizar a biblioteca do Gabinete de Leitura de Jundiaí, 16.01.1945, p. 6-9.

Revista Vernáculo n. ${ }^{\circ} 41$ - primeiro semestre /2018

ISSN 2317-4021 
O parecer da comissão permite observar como estava a situação do acervo, bem como possibilita delinear um panorama da biblioteca do Gabinete de Leitura em períodos anteriores a 1945. Para que a comissão pudesse desenvolver seu trabalho de organização, foi previamente solicitada à diretoria a elaboração de um balanço das reais condições do acervo, de modo a evidenciar os livros faltantes, para que a referida comissão não fosse responsabilizada quando da sinalização das obras não constantes no acervo.

Esse balanço foi realizado em 1938 e, a partir de 1945, deu-se início à tentativa de se reorganizar a biblioteca.

Como se pode verificar no parecer, os livros eram organizados em sequência numérica e a "tradição oral" - ou seja, os "rumores" dizia que cada bibliotecário construíra sua própria lógica de ordenação, tendo como parâmetro apenas o número (milhar) para indicar a entrada de novos livros, sem, contudo, se preocuparem com os livros que porventura tivessem sido descartados pelo desgaste, não devolvidos ou até mesmo furtados da biblioteca. Desse modo, os números faltantes nas estantes não eram reordenados, fazendo com que a biblioteca registrasse a existência de 4.989 livros em 1945, porém tendo verdadeiramente em suas estantes 3.858 livros. Essa prática configurava-se como uma "tradição", de cujo método os bibliotecários, segundo o parecer, sempre se utilizaram, para organizarem a biblioteca, possivelmente desde 1908.

O parecer sinaliza ainda que a ordenação da biblioteca seria feita pelo gênero literário de cada livro, mas se contradiz, ao mencionar 
que o presidente do Gabinete de Leitura, Benedito Ferraz, ordenara que os novos livros que entrassem para a biblioteca fossem alocados nas numerações faltantes, de modo a zerar o número de livros vagos nas estantes. E dava continuidade à sequência numérica, a partir do número 4.990, onde a obra O Rio de Janeiro do Meu Tempo, do autor Luiz Eduardo, marcava o fim de uma desordem e o começo de uma nova ordem para o acervo, mas, ainda assim, seguindo a lógica tradicionalmente praticada.

Esse modo de ordenação certamente ocasionava contratempos, haja vista a falta de 1.131 livros na biblioteca. Todavia, essa "coerência" de organização reforça os motivos pelos quais os leitores não poderiam manusear os livros, e certamente a disposição do acervo, retratado na imagem de 1926, era a forma "tradicional" de se manter a estrutura física da biblioteca. $\mathrm{O}$ fato de haver um balcão e as estantes com os livros estarem atrás dele, sob a supervisão do bibliotecário e de seus encarregados, intermediando a relação entre leitores e livros, demonstra como as partes (livros) do todo (acervo) não estavam ordenadas de modo objetivo, em vista da sua localização e da impossibilidade de posterior recolocação nas estantes pelos próprios leitores.

Para Milanesi, "é o bibliotecário quem estabelece os critérios de organização e os transforma em algo concreto: a biblioteca" ${ }^{20}$.

${ }^{20}$ MILANESI, Luís. Ordenar para Desordenar, p. 35.

Revista Vernáculo n. ${ }^{\circ} 41$ - primeiro semestre /2018

ISSN 2317-4021 
Provavelmente, os critérios para arranjar o acervo do Gabinete de Leitura ainda não estavam totalmente definidos.

Em abril de 1947, a bibliotecária Ida Lehner enviava um oficio aos diretores da instituição, propondo seu ordenado, método de trabalho e o material que precisaria para classificar os livros por ordem de assunto e, assim, poder arrumá-los dentro da biblioteca.

Levando-se em consideração que o leitor vai buscar, no interior das possibilidades temáticas de uma biblioteca, o seu específico objetivo, Ilda Lehner, consultada pelos diretores, propunha lógicas de ordenação mais usuais e práticas, para que fossem implementadas na biblioteca do Gabinete de Leitura:

Considerando que um ordenado mensal de um bibliotecário varia a partir de $\mathrm{Cr} \$ 950,00$, proponho que, durante os meses de duração do serviço de organização da biblioteca me sejam pagos pelo menos $\operatorname{Cr} \$ 850,00$ mensais. O serviço não poderá ser por menos, uma vez que consta do seguinte: classificação dos livros por ordem de assuntos e arrumação geral dos mesmos por essa classificação; catalogação e organização de um fichário dicionário, em que os livros poderão ser procurados pelo título, autores, colaboradores, assunto, etc.; organização de um perfeito serviço de retirada e devolução de livros, debaixo do maior controle possível; organização da secção de referência da biblioteca (obras como enciclopédias, dicionários, anuários, almanaques, bibliografias, de consulta imediata e que devem estar à inteira disposição do leitor); secção infantil - o aproveitamento da que já existe, com a aplicação dos mesmos métodos usados na biblioteca dos adultos, para acostumar as crianças ao gôsto pela consulta disciplinada.

Revista Vernáculo n. ${ }^{\circ} 41$ - primeiro semestre /2018

ISSN 2317-4021 
Auxiliares - o trabalho mecânico de confecção de fichas, seu desdobramento, cartões de leitores, etc., deverá ser feito por duas datilógrafas competentes, pelo menos.

Material - a média de fichas por livro, conforme as adquire a Biblioteca Pública Municipal de Campinas, recentemente fundada pela Escola de Biblioteconomia, é de 10 fichas. Há livros que não necessitam de mais de 5 fichas, mas em compensação há outros que precisam de 100 ou mais.

Para o acervo de 7.000 volumes do Gabinete de Leitura, serão necessárias, portanto, 70.000 fichas de cartolina, à razão de $\mathrm{Cr} \$ 5,00$ o cento. $(\mathrm{Cr} \$ 3.500,00$ de fichas).

Há ainda os impressos: cartões de livros (bookcards), cartões de registro de leitores, cartões de revistas, de reserva de livros, etc., que devem ser comprados em número suficiente para atender a todos os leitores do Gabinete de Leitura.

Dois livros indispensáveis que devem ser adquiridos "Classificação de Mevil Dewey", obra norteamericana no valor de $\mathrm{Cr} \$ 400,00$ e a "Tabela de Cutter", no valor de Cr\$150,00. Se a verba de modo algum permitir a compra do primeiro, pelo menos o segundo deve ser comprado. Essa tabela põe em ordem alfabética dos autores os livros, já arranjados por assunto. A "Classificação Dewey", pode em último caso ser substituída, naturalmente com desvantagem, por outras menores editadas pelo Instituto Nacional do Livro, e que o Gabinete já possui.

Duração do trabalho - levando-se em conta que a biblioteca pública de Campinas, com um acervo inicial de 3.000 volumes, foi entregue ao público em 3 meses, tendo auxiliado na catalogação de livros as alunas de Biblioteconomia, e na confecção funcionários do Instituto Agronômico, cremos que o nosso trabalho levará cerca de 8 meses para ficar completo. É claro que, quanto maior for o número de

Revista Vernáculo n. ${ }^{\circ} 41$ - primeiro semestre /2018

ISSN 2317-4021 
auxiliares, tanto mais curto será o espaço de tempo que tomará a organização do Gabinete de Leitura ${ }^{21}$.

Tendo em consideração a temporalidade (1947), a proposta de Ida interligava-se aos avanços do campo de estudos da Biblioteconomia, baseando-se em recursos lógicos, práticos e manuais.

A partir de seu trabalho, a biblioteca do Gabinete de Leitura seria amplamente classificada, ordenada por assuntos, as crianças teriam sua própria seção para consultas e possivelmente os leitores poderiam manusear os livros entre as estantes, uma vez que, dentro da lógica de ordenação, os livros seriam localizados facilmente e facilmente poderiam ser devolvidos às estantes.

Seguramente o tempo necessário para a realização desse trabalho de classificação e os valores que seriam gastos com o ordenado da bibliotecária, fichas de catalogação e auxiliares, levaram os diretores do Gabinete de Leitura a recusarem a proposta.

Em fevereiro de 1957, o bibliotecário José Pacheco desenvolvia um catálogo de obras (nacionais e estrangeiras) para a biblioteca do Gabinete de Leitura ${ }^{22}$. Esse material era produzido de forma manual e ainda mantinha a mesma lógica de ordenação do início da formação do acervo, sequência numérica, ou seja, nenhum investimento para a melhoria na organização do acervo havia sido feito.

${ }^{21}$ Ofício de Ida Lehner, 05.04.1947.

${ }^{22} \mathrm{Em}$ nenhuma das atas de reuniões consultadas há menção sobre a elaboração de um catálogo de obras. Levando-se em consideração que muitos documentos do Gabinete de Leitura foram perdidos em 1924, o catálogo de obras produzido em 1957 é o único registro que permite observar os livros que compunham o acervo da instituição.

Revista Vernáculo n. ${ }^{\circ} 41$ - primeiro semestre /2018

ISSN 2317-4021 
9.027 obras foram listadas numericamente pelo bibliotecário $(8.090 \mathrm{em}$ português e 937 em línguas estrangeiras), tendo a descrição dos títulos e autores.

Esse catálogo resistiu ao tempo. E, no processo desta pesquisa, essa fonte configurou-se como uma gama de informações a serem ordenadas e interpretadas.

Segundo Milanesi, "ordenar o caos da informação é a única possibilidade de dar sentido a um determinado universo informativo"23. Assim, a pesquisa observou, no catálogo de obras, a possibilidade de se traduzir o acervo do Gabinete de Leitura na síntese dos livros comprados (ao longo de 49 anos, 1908-1957) de acordo com as preferências dos sócios (leitores) da instituição. Mesmo aqueles que eram doados o foram por pessoas que praticavam a leitura, frequentavam o Gabinete e se apropriavam de seu acervo, doando livros na expectativa de vê-lo crescer e se diversificar em gêneros literários.

Certamente muitos livros, em decorrência da passagem do tempo, não constavam mais no acervo, quando da elaboração do catálogo em 1957. Contudo, José Pacheco registrava na página inicial do catálogo: "as obras que aqui serão descritas compõem desde o acervo inicial do Gabinete de Leitura até presente momento $(28 / 02 / 1957){ }^{24}{ }^{24}$

${ }^{23}$ MILANESI, Luís. Ordenar para Desordenar, p. 36.

${ }^{24}$ Catálogo de Obras do Gabinete de Leitura de Jundiaí, 1957, p. 1.

Revista Vernáculo n. ${ }^{\circ} 41$ - primeiro semestre /2018

ISSN 2317-4021 
Em partes, esse catálogo possibilita uma leitura sobre o que poderiam encontrar os sócios e frequentadores para lerem na biblioteca, dentro do recorte espaçotemporal desta pesquisa.

No campo da historiografia, os estudos sobre bibliotecas tendem a apresentar os leitores. A partir dos registros de consultas e retiradas de obras, as pesquisas identificam e qualificam aqueles que buscavam impressos para lerem ${ }^{25}$.

Como citado anteriormente, os bibliotecários do Gabinete de Leitura de Jundiaí eram responsáveis pela guarda e organização do acervo. Tinham, dentre suas tarefas, a incumbência de registrar as obras mais consultadas e de fazer um balanço do quadro geral da biblioteca, para apresentarem anualmente. Esses documentos, no entanto, se perderam ao longo do tempo, impossibilitando uma aproximação direta com o universo de livros, leitores e suas práticas de leituras.

Em consulta às atas de reuniões e averiguando-se a prática de comprar livros para a biblioteca, pautada nas escolhas dos sócios e seus possíveis gostos literários, o olhar sobre o acervo possibilitou a esta pesquisa delinear um panorama do que os sócios poderiam encontrar para ler de acordo com suas escolhas.

Vale destacar ainda que não havia uma pesquisa minuciosa acerca da biblioteca, na perspectiva de interpretação do catálogo de obras. Isso provocou certa dificuldade na condução da análise.

${ }^{25}$ ROCHA, Débora Cristina Bondance. Bibliotheca Nacional e Pública do Rio de Janeiro: um ambiente para leitores e leituras de romance (1833-1856). Campinas, 2011. 347 p. Dissertação (Mestrado em Teoria e História Literária). Unicamp, 2011.

Revista Vernáculo n. ${ }^{\circ} 41$ - primeiro semestre /2018

ISSN 2317-4021 
Com vistas a encontrar uma direção, em meio a tantas informações, algumas escolhas foram necessárias. Diante de uma fonte como esta, com uma imensa quantidade de informações, era preciso cautela. Era necessário escolher um caminho para trabalhar com essa vasta fonte primária.

O sistema de CDD foi então adotado como uma lógica para se ordenar o catálogo de obras, uma vez que adotá-lo como meio de ordenação já havia sido cogitado na história da biblioteca do Gabinete de Leitura de Jundiaí.

A partir das obras descritas, foram identificados os títulos e classificadas tais obras, de acordo com os gêneros literários. Esta identificação foi feita a partir da consulta em dicionários bibliográficos, catálogos de bibliotecas on-line, em dados de outras pesquisas e em sites de busca na internet, ordenando as obras em planilhas de Excel. Ao final, obteve-se um panorama dos gêneros literários e suas predominâncias dentro da biblioteca.

Foi possível ainda listar os autores com maior número de obras, dentro das classificações principais. Os autores possuem menos ou mais títulos em cada classificação, então, para cada uma, foi estabelecido um número de corte, de forma que tornasse possível apresentá-los em gráficos. Fez-se também uma breve descrição de alguns de seus títulos, atentando-se para o fato de que as datas de publicações, às vezes informadas, não eram necessariamente as datas 
em que esses livros haviam entrado para a biblioteca do Gabinete de Leitura.

O catálogo de obras em português possui uma sequência numérica com 8.090 títulos descritos, não separados por volumes. Deste total, 44 títulos estavam em branco (sem a descrição do título e autor) e 3 não foram possíveis de se identificar, pois as descrições estavam ilegíveis. Portanto, foi realizada a classificação de 8.043 títulos nacionais.

O catálogo de obras em línguas estrangeiras (937 obras) foi apenas organizado de modo a demonstrar o número de livros para cada língua (inglês, francês, italiano, espanhol e alemão), sem, contudo, separá-los por gêneros literários.

\section{As preferências de leituras}

Iniciando-se com o catálogo de obras em português, produzido em 1957, a biblioteca do Gabinete de Leitura de Jundiaí, após a sua ordenação segundo a CDD, apresenta a seguinte composição em seu acervo:

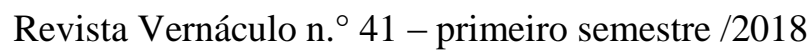

ISSN 2317-4021 


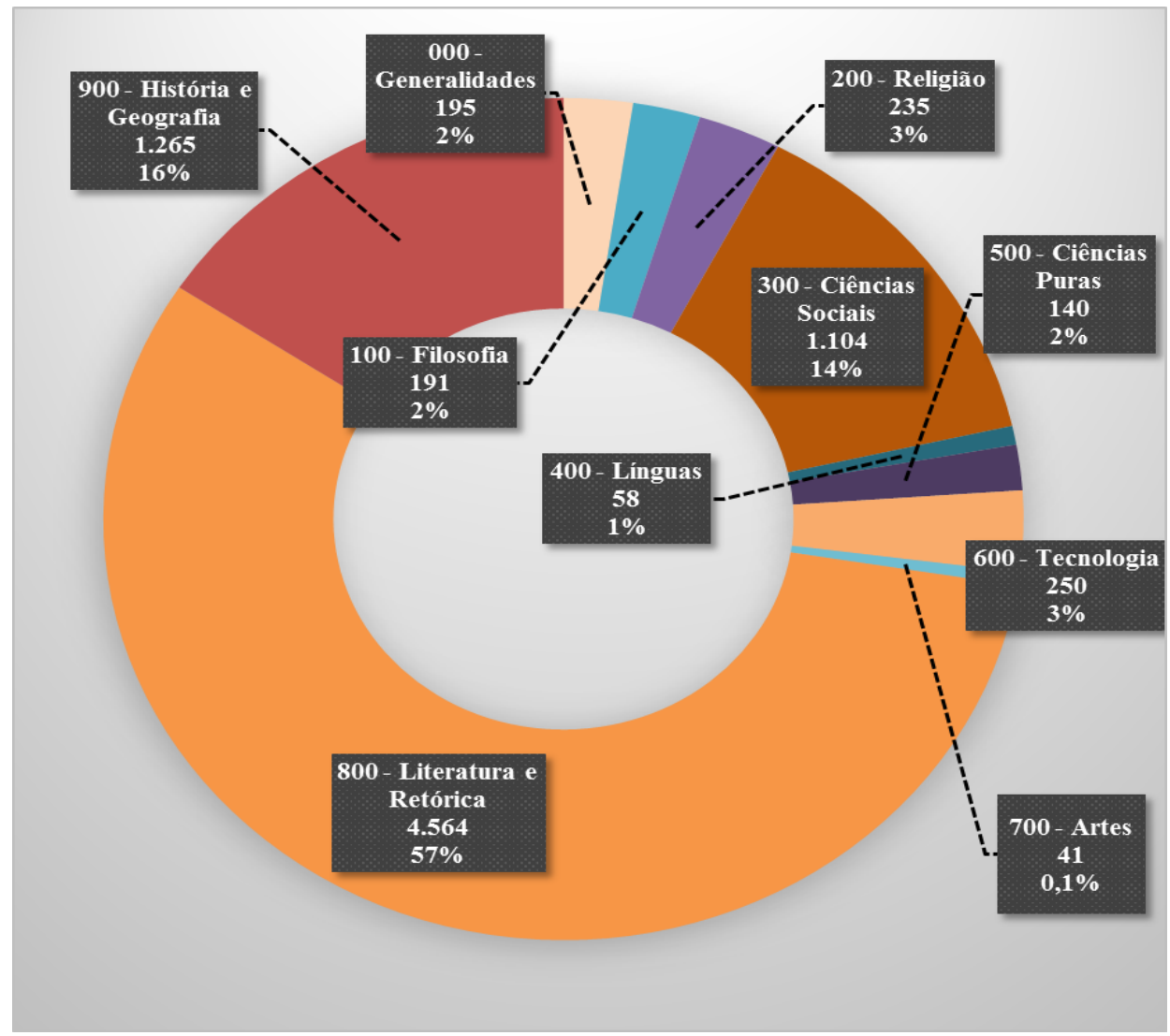

Gráfico 1 - Divisão da quantidade de obras e sua (\%) por área do conhecimento Fonte: Elaborado pelo autor

Um dos aspectos que se destacam na observação do acervo é seu traço leigo. O baixo número de obras religiosas (3\%) dentro do espaço de leitura que o Gabinete representava, em Jundiaí, evidencia seu caráter laico, justamente em um momento em que Igreja e Estado atuavam em posições separadas, na esfera pública, desde a instauração do regime republicano.

Revista Vernáculo n. ${ }^{\circ} 41$ - primeiro semestre /2018

ISSN 2317-4021 
A cultura religiosa (fosse o catolicismo ou o protestantismo) ainda possuía forte presença nas questões sociais, nas primeiras décadas do século XX. Particularmente no que se refere à educação (pública e particular), mecanismo de preservação e manutenção da moral, dos costumes e das tradições cristãs. Todavia, aos poucos, espaços e instituições seculares, como o Gabinete de Leitura, faziam emergir grupos letrados, cada vez mais envoltos nas transformações da época (trabalho livre, ideais liberais, urbanização, avanços científicos e tecnológicos, entre outras) e menos nas condutas e devoções religiosas.

Significativa a presença de obras de Ciências Sociais (14\%) e História (16\%). A primeira classificação era composta, em sua maioria, de estudos sobre ciências políticas, demonstrando o interesse do público leitor em compreender o cenário político e econômico da nação por meio dos livros. Há que se ter em consideração que o quadro societário do Gabinete de Leitura era preponderantemente masculino, portanto, um público leitor que de fato se apropriava das questões públicas, fosse movido pelo próprio interesse ou pelas prescrições da vida social, que delegavam à figura masculina o conhecimento sobre os impasses da esfera pública.

A presença das mulheres não era proibida na instituição, mas não figuraram no quadro societário, ao menos no período aqui analisado. Contudo, certamente estavam presentes entre o público leitor. Os livros sobre educação, instrumentos auxiliadores no processo da educação, instruindo e alfabetizando, também compõem

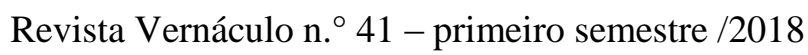

ISSN 2317-4021 
significativamente esse percentual. O projeto de educação do Gabinete de Leitura seguramente se valeu de suas obras pedagógicas para promover os estudos das primeiras letras.

A segunda classificação (História) traz em questão o possível apreço dos leitores pelo conhecimento sobre a formação da nação e seus desdobramentos sociais, levando-se em consideração que os títulos sobre História do Brasil possuem maior proporção (48\%) dentre os livros de História.

O processo de transição brasileira do sistema agrário-comercial para o urbano-industrial notadamente fazia com que novos arranjos fossem sentidos e experienciados, somando-se ainda a esse processo os embates frente às representações políticas, levando os cidadãos ao interesse, cada vez maior, sobre a identidade, a cultura e as sociedades brasileiras.

Notável também o predomínio da classificação Literatura e Retórica (57\%), em que o gênero romance prevalece, sobretudo com títulos nacionais e estrangeiros (franceses e ingleses) que caracterizam a figura feminina com enlaces de amor, paixão, sonhos e desejos. Histórias romanceadas e que remetem à presença da mulher dentro do Gabinete de Leitura. Os demais gêneros aparecem em menor proporção, porém marcam ainda a diversidade dos temas presentes nas estantes da biblioteca, possibilitando aos leitores aprenderem a ler, a escrever e a falar ou a aprimorar essas ações.

Revista Vernáculo n. ${ }^{\circ} 41$ - primeiro semestre /2018

ISSN 2317-4021 
Importante ressaltar que os 9.027 livros descritos no catálogo aos poucos foram se somando, entre compras e doações, para comporem em sua totalidade o acervo do Gabinete de Leitura.

A biblioteca teve um aumento de $82 \%$ em seu número de livros de 1908 até 1957, quando o catálogo foi produzido. O crescimento deuse de modo gradativo e natural, certamente com muitas perdas e descartes, no decorrer do tempo, mas acompanhando o próprio desenvolvimento da Instituição ${ }^{26}$. Em 1922, apresentava 5.271 volumes, segundo o Anuário Estatístico de São Paulo para aquele ano; portanto, se infere que aproximadamente mais da metade (58\%) dos livros que compunham o acervo, naquele período, puderam ser ordenados por esta pesquisa por gêneros literários, permitindo uma leitura sobre o que os sócios e frequentadores do Gabinete de Leitura "preferiam" e "poderiam" encontrar para ler.

O catálogo de obras em língua estrangeira apresenta a seguinte composição:

${ }^{26}$ A título de curiosidade, atualmente o Gabinete de Leitura conta com 45.000 volumes.

Revista Vernáculo n. ${ }^{\circ} 41$ - primeiro semestre /2018

ISSN 2317-4021 


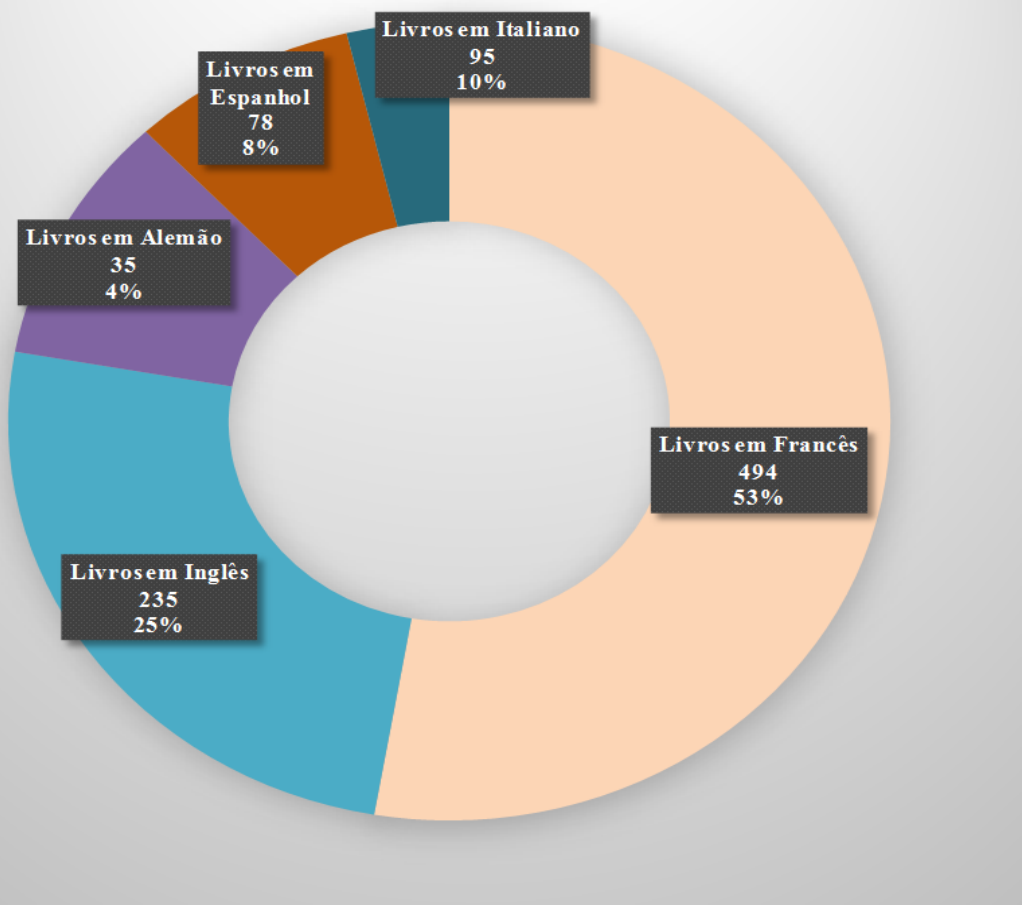

Gráfico 2 - Divisão da quantidade de obras por língua estrangeira e sua (\%) Fonte: Elaborado pelo autor

Os livros em francês representam mais da metade (53\%) dos livros em língua estrangeira dentro do acervo. O número de franceses associados ao Gabinete de Leitura sempre foi baixo: 6 foi a quantidade máxima de sócios franceses registrados no Gabinete de Leitura em 1913, o que contrastava com a abundância de livros em idioma francês que podia ser notada, não somente nas estantes do Gabinete de Leitura, como também em diversas livrarias brasileiras ao final do século XIX e início do XX. Entre os autores listados constam Alexandre Dumas, Xavier de Montépin, Vitor Hugo, Eugene Sue, Germaine Acrement, 
Ponson Terrail, Maurice Maeterlinck, Gustave Flaubert, Moliére, Émile Zola, Honoré de Balzac, entre outros.

Os ingleses também não tiveram grande presença entre os sócios da Instituição, que registrava a existência de apenas 2 ingleses em seu quadro societário, entre 1914 e 1917. Apesar disso, as obras em idioma inglês constituíam 25\% dos livros estrangeiros. Entre os autores aparecem Berta Ruck, W. Somerset Maugham, Baroneza Orczy, Samuel Smiles, Oscar Wilde, Arthur Conan Doyle, Walter Scott, Sax Rohmer, Charles Dickens e Anne Kelly.

Livros em língua italiana representam 10\% de obras no acervo. Os autores que mais figuram são Pitigrilli, Ignazio Silone, Giovannino Guareschi, Mário Soldati, Ricardo Bacchelli, Giovanni Boccaccio, Dante Alighieri, Lorenzo Gualtieri, Alessandro Manzoni, Justino de Montalvão, Luigi Pirandello, Ferdinando P. Della Gattina e Carolina Invernizio.

Dentre os livros espanhóis, que representam $8 \%$, constam os autores Enrique Perez Escrich, Vicente Blasco Ibánez, Miguel de Cervantes e Concha Linares Becerra. Dos livros em alemão (4\%) aparecem os autores Marie Von Ebner Eschenbach, Paul Oppenheim, Gustav Schwab, Franz Von Seeburg, Goethe e E. Marlitt.

\section{Considerações}

A análise sobre o acervo de obras da biblioteca do Gabinete de Leitura de Jundiaí revelou as preferências literárias dos leitores. Mesmo 
com as especificidades dessa fonte, sua produção fora do período de análise desta pesquisa (1957), as perdas e os descartes de livros ao longo do tempo, a lógica de ordenação numérica, desfavorável a uma compreensão geral sobre os gêneros literários, foi possível reordenar a fonte Catálogo de Obras, classificá-la e apresentar os principais gêneros literários existentes.

Este trabalho com o catálogo de obras evidenciou a predominância de áreas do conhecimento como Ciências Sociais, História e Literatura/Retórica. Para esta última, o gênero Romance prevalece, demonstrando o interesse do público leitor por essas temáticas e a presença do público leitor feminino.

Quem eram essas leitoras e como os livros de romances poderiam indicar suas presenças no Gabinete de Leitura?

Tentar responder a essas questões não é tarefa simples, pois as fontes de que a pesquisa dispõe não as solucionam diretamente. Porém, é possível notar alguns indícios.

Uma das possibilidades de se perceber a presença das mulheres é através do próprio quadro societário da instituição. Muitos sócios do Gabinete de Leitura eram homens mais velhos, certamente casados e pais, como demonstraram os prontuários dos que eram funcionários da Companhia Paulista.

Revista Vernáculo n. ${ }^{\circ} 41$ - primeiro semestre $/ 2018$

ISSN 2317-4021 
Das 112 fichas consultadas, 55 constavam como casados e com filhos $^{27}$. Portanto, esse panorama permite levantar, como possibilidade, a frequência de esposas e filhas no Gabinete de Leitura, cujo marido e/ou pai era associado. Caso não fossem pessoalmente, os livros poderiam ser tomados de empréstimo e devolvidos após dez dias, permitindo diversas formas de se praticar a leitura do impresso.

Outra possibilidade é que o Gabinete de Leitura possuísse dois horários para frequentação pública, (das $08 \mathrm{~h}$ às $10 \mathrm{~h}$ e das $19 \mathrm{~h}$ às $21 \mathrm{~h}$ ). Desse modo, moças e mulheres de Jundiaí também poderiam se dirigir à instituição e realizar a leitura dos livros.

Há que se considerar também que a própria existência predominante desses romances na biblioteca demonstra que as compras de livros realizadas pelas comissões privilegiavam o gênero romance. Com a possibilidade de os sócios interferirem nas escolhas dos títulos, certamente levavam em consideração as preferências de seus familiares (dentre eles as mulheres). A constante procura e consulta desses livros por outras frequentadoras da instituição visava a atender o interesse desse público.

Desse modo, o acervo caracteriza-se como o indício mais forte da presença das mulheres. Porém, levando-se em consideração as palavras de Martins, é certo que o gênero romance também era muito apreciado pelo público masculino.

${ }^{27}$ LANNA, Ana Lúcia Duarte. Ferrovia, Cidades e Trabalhadores: a conquista do oeste (1850-1920). Banco de dados de funcionários, 2002. 1 CD-ROM.

Revista Vernáculo n. ${ }^{\circ} 41$ - primeiro semestre /2018

ISSN 2317-4021 
Em São Paulo, reduto dos ideólogos da República, à parte o universo do jornal, lia-se muito romance, do folhetim de capa e espada de Alexandre Dumas ao romantismo brasileiro de José de Alencar, do realismo português de Eça de Queiroz ao naturalismo francês de Emile Zola. Muitos divulgados pelos publicistas ${ }^{28}$.

Desse modo, não faltaram suportes materiais para que os romances pudessem circular, e certamente no acervo do Gabinete de Leitura de Jundiaí homens e mulheres se apropriaram desse gênero literário.

A figura da mulher pouco foi citada nas fontes consultadas, porém, isso não silencia ou minimiza suas participações nas dependências do Gabinete de Leitura; certamente elas estavam presentes, atuaram de diferentes maneiras, de modo indireto e de interferências múltiplas. Contudo, esta pesquisa pode apenas perceber os indícios de suas presenças na biblioteca do Gabinete de Leitura, através da predominância do gênero romance e pelos títulos dessas obras, onde a mulher era o personagem principal.

O caminho escolhido para o desenvolvimento desta análise representa apenas uma das possibilidades de percurso. Olhar o surgimento do Gabinete de Leitura de Jundiaí como um elemento representativo de uma realidade social em construção, por um grupo de trabalhadores ferroviários, para servir como um espaço de letras a outros grupos sociais foi uma possibilidade de investigação

${ }^{28}$ MARTINS, Ana Luiza. Op. cit., p. 305.

Revista Vernáculo n. ${ }^{\circ} 41$ - primeiro semestre $/ 2018$

ISSN 2317-4021 
historiográfica selecionada por esta pesquisa. No entanto, muitos outros caminhos poderiam ser trilhados para que se pudessem traçar outras abordagens e que possibilitassem outras compreensões sobre este múltiplo objeto de estudo, o Gabinete de Leitura.

\section{Referências}

ANUÁRIOS Estatísticos de São Paulo, 1910-1926.

CHARTIER, Roger. A aventura do livro: do leitor ao navegador. São Paulo: Editora UNESP, 1999.

Lisboa: Difel; São Paulo: Bertrand, 1990.

CRUZ, Heloisa de Faria (Org.). São Paulo em Revista: catálogo de publicações da imprensa cultural e de variedades paulistana - 1870-1930. (Coleção memória, documentação e pesquisa, 4). São Paulo: Arquivo do Estado, 1997.

DARNTON, Robert. O beijo de Lamourette: mídia, cultura e revolução. São Paulo: Companhia das Letras, 2010.

O Gabinete: Orgam do Gabinete de Leitura Jundiahyense. Anno I, $\mathrm{N}^{\circ} 1$,

LIVRO de Registro das Atas da Diretoria do Gabinete de Leitura de Jundiaí, 1908-1957.

LIVRO de Registro das Atas de Assembleia Geral do Gabinete de Leitura de Jundiaí, 1908-1957.

MANGUEL, Alberto. A biblioteca à noite. São Paulo: Companhia das Letras, 2006.

MARTINS, Ana Luiza. Gabinetes de Leitura da Província de São Paulo: a pluralidade de um espaço esquecido (1847-1890). São Paulo, 1990. 370 p. Dissertação (Mestrado em História) - FFLCH-USP, 1990.

Revista Vernáculo n. ${ }^{\circ} 41$ - primeiro semestre /2018

ISSN 2317-4021 
MILANESI, Luís. Ordenar para Desordenar: centros de cultura e bibliotecas públicas. Editora Brasiliense, 1986.

POLASTRON, Lucien X. Livros em chamas: a história da destruição sem fim das bibliotecas. Rio de Janeiro: José Olympio, 2013.

ROCHA, Débora Cristina Bondance. Bibliotheca Nacional e Pública do Rio de Janeiro: um ambiente para leitores e leituras de romance (1833-1856). Campinas, 2011. 347 p. Dissertação (Mestrado em Teoria e História Literária) - Unicamp, 2011.

SCHAPOCHINK, Nelson. Os Jardins das Delícias: Gabinetes literários, bibliotecas e figurações da leitura na Corte Imperial. São Paulo, 1999. 269 p. Tese (Doutorado em História) FFLCH-USP, 1999.

Recebido em 31/05/2017, aceito para publicação em 08/08/2017.

Revista Vernáculo n. ${ }^{\circ} 41$ - primeiro semestre /2018

ISSN 2317-4021 